\title{
Towards an Integrated Model for the Competitive Strategies
}

\author{
Hamed Omar Abdalla ${ }^{1}$ \\ ${ }^{1}$ Department of Management, The World Islamic Sciences \& Education University, Jordan \\ Correspondence: Department of Management, The World Islamic Sciences \& Education, University, P. O. Box \\ 1101, Postal Code 11947, Amman, Jordan. E-mail: h_abdkan@yahoo.com
}

Received: November 14, 2014

Accepted: December 16, 2014

Online Published: January 20, 2015

doi:10.5539/ijbm.v10n2p236

URL: http://dx.doi.org/10.5539/ijbm.v10n2p236

\begin{abstract}
The research aimed to determine and evaluate the importance of the competitive strategies' classifications that the managerial thought has presented so far. It also aimed to provide a comprehensive model for these strategies which is based on a primary rule of determining all the organizations' community categories comprehensively, and all the competitive strategies that should be utilized to deal with every category of those categories. A content analysis methodology was employed and a final conclusion was reached: that none of those classifications could provide comprehensive perception of the competitive strategies system which deserves every organization's interest while managing relations with its markets. It was found that the model divides the population into four categories: category of loyalists to organization's commodities, category of irresolute people to organization's commodities, category of disinterested people to organization's commodities and category of people who boycott the organization's commodities. All the competitive strategies pertinent to every division were determined too.
\end{abstract}

Keywords: competitive strategies model, strategic dimensions, population categories strategies

\section{Introduction}

The killing of Abel on the hands of his brother Cain is considered an evidence on the truth that conflict and competition are rooted cases in human nature, whether represented in the relation among individuals, groups, organizations or countries, because they are eventually governed by the various interests and goals of the individuals who their human nature and state is invariant from the nature and the state of Abel and Cain; It is the state of survival conflict where the survival favors the strongest, and perhaps all the human history epochs with all what they have witnessed of conflicts on the level of all the human communities and civilizations are the most important evidence on that matter.

Despite the fact that the survival is for the fittest, the subjects of conflict management and competition management have not categorized as special and important topics.

However, these topics recently became an important topics in the fields of managerial and economic research in the past few decades, particularly in the nineties of the last century when the concept of Globalization emerged. Competition became the dominant factor for all the relations between the business organizations in all levels weather it is local, regional, and international. Every organization started to face a profound challenges that threatened its existence, a matter that pushed every organization to think comprehensively and creatively on how to overcome those challenges, as well as, putting strategies for managing its competitive relations in order to guarantee its survival and progress with the assistance of specialized experts and councilors to achieve these goals.

Did the business organizations succeeded in determining the strategic dimensions that they have to take care for while managing their competitive relations? And, was it possible for experts and researchers to build competitive strategies in a way that it is distinguished with objectiveness and comprehensiveness?

The answer to these questions is the target of this study.

\subsection{The Problem}

There have been a lot of studies that tackled the concept of competitive strategies, and also the suggestions (models) that those studies provided. Nevertheless the most important fundamental critiques that they have faced are failed to provide a comprehensive model (integrated), such that business organizations could themselves be 
guided by its vocabulary while building their competitive strategies which guarantee to every one of them its terms and elements of survival and evolution. Therefore, it may be possible to work on design a comprehensive and an integrated model which help solving such case.

\subsection{Goals and Significance}

The research importance stems from its endeavor to achieve the following goals:

- Determine the most important classifications that the managerial thought has presented on the competitive strategies and evaluate them.

- Provide an integrated model which would help business organizations that are interested in building competitive strategies that are marked with comprehensiveness and substantiality.

\subsection{Research Questions}

- What are the most important requirements to ensure a practical management of the competition process effectively and successfully?

- What are the most important intellectual contributions in the field of determining the competitive strategies?

- Could an integrated and substantial model be built for the competitive strategies which could be a comprehensive guide for the business organizations?

\subsection{Research Methodology}

a content analysis methodology was determined and studies the importance of the classifications that the managerial thought has presented so far regarding the competitive strategies, then evaluate them, to a finally reach a conclusion that none of those classifications could provide a thorough and comprehensive perception of the system of the competitive strategies that every organization should be interested in while managing its relations with the market it work within..

\subsection{The Competition Concept}

There are numerous definitions related to this concept, almost vary in their expressions with the variation of the researchers (approaches), and despite that pluralism it is possible to determine the primary elements which support the integrated and objective definition, as follows:

- Competition is the other face of the conflict, and the conflicted parts turn into competitive part when no part is able to abolish the other parts. Nevertheless, when the moment that any part is able to attack and abolish the part then the case would turn confiscatory. Thus, the competition is considered a jelly state that floats on the surface when the powers of the other parts are equivalent, and transform into a conflict when the powers imbalance. (It is the state of acceptance of the business-with philosophy as long as it is impossible to work with the substitute-for philosophy).

- It presumes the ability to evaluate the powers of the competitive parts, and the ability to determine their competitive position on the map of the competitive powers.

- It presumes the ability to deal with the various competitive positions, and to keep their relevant competitive position.

- They differ in their self-expression manifestation; the competition could have an offensive image, or counter attack with the purpose of protecting the particular position from any threat, or in a defensive competition to protect that position.

Consequently, competition could be defined as: an expression of the equivalent conflict that impose on a relevant organization the work on conducting continuous evaluations of the powers of the other organizations which stand against it in one conflict arena, determining their positions, and taking the necessary offensive or defensive measures which will enable it to keep its position, then working on enhancing and extending that position whenever possible.

\section{Literature Review}

\subsection{Competition Process Management}

For the beginning, we have to indicate that managing this process varies according to the philosophy that the relevant business organizations embrace, and according to the prevalent philosophy within the community those organization belong to. In the organizations or the liberal communities which make the freedom value a fundamental supreme value, have their pistols hanged down their wests and shoot fire from them before trying to assign their targets, individualists, love competition, and hold games for it sake. Thurow (1992) indicates that the 
workers in such organizations also are not considered members in a team because antagonism relations are part of the system. Duncan (1989) summarizes the eventual outcome of competition and conflict practice "we become effective enemies to ourselves when we stop cooperating!"

On the other hand, the Japanese organizations and the organizations that works on basis of cooperation philosophy, any competition that leads to conflict is prohibited within these organizations, However, competition is allowed when it is with a competing foreign organizations that look like enemies on the chessboard (Najem, 2006). That is clearly highlighted in the "Islamic model (I)" where competition is prohibited within the system except for matters of worship and benevolence "And cooperate in righteousness and piety, but do not cooperate in sin and aggression. And fear Allah; indeed, Allah is severe in penalty" (HolyQur'an, Surat Al-Mā'idah, 2), "They will be given to drink [pure] wine [which was] sealed. The last of it is musk Singer, 2013). So for this let the competitors compete (The Holy Qur'an, Surat Al-Muțaffifin, 83), whereas it completely opened in the relation with the non-Islamic communities that lie off the system (Assaf, 2013).

Meanwhile, management of the effective competition process assumes the following primary requirements:

First, the ability to determine the challenges that face the business organization and how to determine its volume, its degree of impact, and ways to defy these challenges. One of the most important challenges, what Porter referred to in his framework of industry analysis and the five forces: the threat of established rivals, the threat of substitute products or services, the bargaining power of customers, the bargaining power of suppliers, and the threat of the conflict between the competitive organizations (Porter \& Heppelmann, 2014).

Second, the ability to possess real competitive advantages that would enable the relevant business organization to achieve superiority over its rivals in the market. the most important characteristics of the competitive advantage are becomes inapplicable to imitation, simulation or even keep pace by the rivals. In order to achieve that, the organization should take the following matters or some of them into consideration:

a. Investment in the available human capabilities, triggering the creativity and innovation in order to reach intellectual creations and artistic innovations that would reflect in a distinguished organizational images, methods, techniques, and models.

b. Organization's possession of a financial position, whether through dependence on its own capabilities, or through what can be gained from the support of the central authority (as in the Japanese model case) in order to build a high production capability that would allow it to flood the market, then reduce its sales cost for an extended time range that the rival organizations cannot cope with, while keeping an adequate of quality that the customers seek.

c. Achieve cheap labor market by relying on the abundant trained Human capacity while substituting to substitute, wherever it's possible, advanced high-cost technologies with limited costs. This will reduce the total cost of production leading to a reduction in the total cost of sales something that other organizations, which does not possess such type labor, will not be able to compete with.

Third, the ability to build competitive strategies that enable the organization to build competitive edge to helping reinforcing its position in the market, as well as, expanding its presence by its abilities to reach new customers continuously.

\subsection{Classifications for the Competitive Strategies}

Organizations differ in terms of how to build their competitive strategies according to the size of every organization, its degree of evolution, and its financial/humanitarian/technological capabilities etc. (the organizational capabilities). All this will reflect in a variety of the way how these organizations deals with the market which already it's selling in or seeking to penetrate and break through.

He put forward a number of classifications for the competitive strategies in the aim of helping business organizations in building their competitive strategies, of them are the following:

1) Porter's classification: Porter stated that it is necessary that all the organization's activities should correspond to the substantial strategy of the organization in order to achieve the organizational effectiveness. Also, he stated that the source of the competitive advantage is represented in the organization's ability to surpass, a matter that can be achieved via the following: (Porter, 1980).

a. Cost leadership Strategy: It is the strategy that aims to build the competitive advantage through market leadership with lowered prices that are achieved by reducing the overall costs of products or services. Organization adopts this strategy when it sees that its capabilities are enough to provide commodities or services with costs less than those of the rivals. Organizations gaining an essential cost advantage over the competitors 
will be able to increase the number of its customers, which will in turn, will result in gaining more market share. This strategy built its competitive advantage on achieving higher profit margin than those of the competitors.

b. Differentiation strategy: It is a strategy that aims to build the competitive advantage on market via product or service differentiation from those of the competitors. The organization adopts such strategy when its capabilities are enough to provide commodities that are distinguished and unique, and in a way that enables it to increase the number of customers who have the willingness to buy the excellent commodities, regardless of their prices. This strategy focuses on making the customers more loyal to its commodities, and making them less sensitive towards their prices.

c. Focus strategy: A strategy that aims to build the competitive advantage through focusing on a segment of the market using one of the two strategies: leadership by overall cost, or differentiation strategy. The organizations refuge to this strategy when it sees that its capabilities are enough to help it target a particular class or category within the industry.

2) Miles \&Snow classification, which is comprised of four strategic competitive strategies: (Miles \&snow, 1978).

a. "Defenders" strategy: It indicates the role that the organization in defending its competitive position in the market. Organizations refuge to such strategy whenever their products or services target a particular segment of the market, and the competitive environment in the market is stable.

b. "Prospectors" strategy: indicates the role that a relevant organization plays in providing creativity and innovation opportunities through $\mathrm{R} \& \mathrm{D}$ prospecting operations, which the organizations that seek differentiation and supremacy often adopt.

c. Analyzers strategy: indicates the role that a relevant organization plays to be able to closely analyze the competitive environment, in order to search for opportunities for hinting creative ideas from the other competitors, such that it will be able to develop products or services that differentiate it in the market without paying efforts and high costs.

d. Reactors strategy: indicated the role a relevant organization plays which would enable it to imitate the others. It is adopted by organizations that do not possess the elements and conditions that are necessary to adopt any one of the previous strategies.

3) Treacy \& Weiserma classification: (Treacy \& Wiersema, 1995). Consultants in marketing, the two researchers presented a new classification for the competitive marketing strategies. The idea of the classification can be summarized in that the organizations can gain the supremacy in the market through providing the highest value to the customer, and to provide such value the organizations can apply one of the three strategies named "the value disciplines", which are represented in:

a. Functional supremacy strategy: guarantees for the organization gaining the supremacy in the market and achieving a supreme value "competitive advantage", which can achieved by the organization's ability to sale its products or services in low prices in the market.

b. Solid relation with the customer's strategy: indicates the necessity of the organization's possessing of a supreme value through helping it precisely divide its markets, and continually adapting the commodities with the needs of the targeted customers.

c. The leading position strategy: indicates the necessity for possessing supreme consumption value, through enabling it to release a flooding and continuing stream of new products or services in the market.

4) Kotler's classification: Kotler presented a new classification in the competitive strategies topic, employing a different methodology to the previous methodologies in this field, as following (Kotler \& Armstrong, 2010):

a. Pioneering organization strategy: adopted by the pioneering organization, which has the initiative to provide the market with new products or services, has the initiative to change prices, has multiple wide distribution channels, and initiate large scale promotion and advertisement campaigns.

b. Challenging organization strategy: adopted by second position organizations in the market (i.e., behind the pioneering). The goal of the challenging organizations lies in rising their market share by acquisition of parts of the market shares of other competitors, via directing focused attacks on the weakness spots in the pioneering organizations and other challenging organizations in the market.

c. Dependent organization strategy: adopted by some organizations that are positioned in the challenge position, and which prefers not to choose an offensive strategy against the pioneering organization, but it works 
on analyzing the pioneering organization behaviors and make use of them in its marketing plans.

d. Specialized organization strategy: adopted by organizations that seek to gain a specified share of the market. It does that by specializing in a specified field that meets the needs and wants of a particular category of customers.

\subsection{Assessment View}

By reviewing the previous models, analyzing and evaluating objectively, we can summarize the followings:

- These models are vary in elements on terms of formal aspects, but they are sharing the same terms of aspect.

- None of the above models be uniquely utilized in the competition process by one organization other than its rivals, and each one that imitated or implemented by organizations is not considered a competitive model.

- None of the above models can help to build comprehensive strategy that takes into consideration all its elements, classes and success in turning them into a group of utterly loyal customers to the organization.

Table 1. Correspondence aspects between the different models of competitive strategies

\begin{tabular}{|c|c|c|c|c|c|c|}
\hline $\begin{array}{ll}\text { Porter's } & \text { model } \\
\text { strategies } & \\
\end{array}$ & $\begin{array}{l}\text { Snow \& Miles Model } \\
\text { Strategies }\end{array}$ & $\begin{array}{l}\text { Treacy \& } \\
\text { strategies }\end{array}$ & Wieserma & $\begin{array}{l}\text { Kotler's model } \\
\text { strategies }\end{array}$ & Matching aspect & \\
\hline $\begin{array}{l}\text { Market leadership by } \\
\text { overall cost }\end{array}$ & Defenders & Functional sup & macy & $\begin{array}{l}\text { Challenging } \\
\text { organization }\end{array}$ & Costs reduction & \\
\hline M L by differentiation & Prospectors & Leading positic & & $\begin{array}{l}\text { Pioneering } \\
\text { organization }\end{array}$ & $\begin{array}{l}\text { Differentiation } \\
\text { products }\end{array}$ & in \\
\hline \multirow[t]{2}{*}{$\begin{array}{l}\text { Market } \\
\text { focus }\end{array}$} & Analysts & $\begin{array}{l}\text { Solid relation } \\
\text { customers }\end{array}$ & with the & $\begin{array}{l}\text { Specialized } \\
\text { organization }\end{array}$ & $\begin{array}{ll}\text { Focusing } & \text { on } \\
\text { particular } & \text { group } \\
\text { customers } & \end{array}$ & \\
\hline & Respondents & & & $\begin{array}{l}\text { Dependent } \\
\text { organization }\end{array}$ & Imitation & \\
\hline
\end{tabular}

\section{The Integrated Model for the Competitive Strategies}

The idea of this model is based on the following primary pillars:

Taking into consideration all the community categories or groups that the organization deals Not to focus only on the category of the customers who deal the organization's products. These categories are divided into the following:

The loyalists to the organization's products or services: It is the category which buy and possess the organization's products and services on regular basis. It is characterized by high degree of loyalty to these commodities even if its products were higher in terms of price than the products or services of the other organizations. Therefore, the category of consumers does not pay much attention to the similar products or services from the competing organizations, rather, this category may work in one way or another on marketing the organization's products to other people.

- The Undecided towards buying the organization's products or services: This is the category of consumers with growing desire to deal with the relevant organizations. Also, they stated to having a growing knowledge of those organizations services and commodities. However, they cannot make a decision in actually buying the product. This reluctance in buying can be a result of many factors, but the most important factor is the availability of similar or alternative commodities provided by other competing organizations which are distinguished with equivalent and competitive advantage characteristics. This leads to uncertainty towards which directions that this category individuals will take while when choosing what to buy.

- The disinterested towards buying the organization's products or services: By far, largest category among the community groups. It is mostly characterized by not having that much of interest in the products features, the nature of the organizations, their nationalities, their goals...etc. Also, the buying capabilities of individuals of this category varies dramatically. What help in making this " not-interested" behavior is the lack of adequate knowledge of the organization's various featured products or services 
which differentiate them from their competitors. Mostly, individuals of this category buy products or services without looking at the trademark or the commercial name. They buy only the products or services that fulfill their instantaneous needs and desires, in accordance with their purchasing capabilities, therefore do not care about commodity source, this organization or other ones.

- The boycotters to the organization's products or services: This is the category of consumers those who have the need to buy the organization's commodities, have the ability to buy, and having a good knowledge of the organization and its commodities, nevertheless, they intentionally they object and boycotts buying its commodities. This is a direct result of being loyalty to other competing organization's commodities, for some social or political considerations,.... etc.

The following figure represents the four different categories in this model targets:

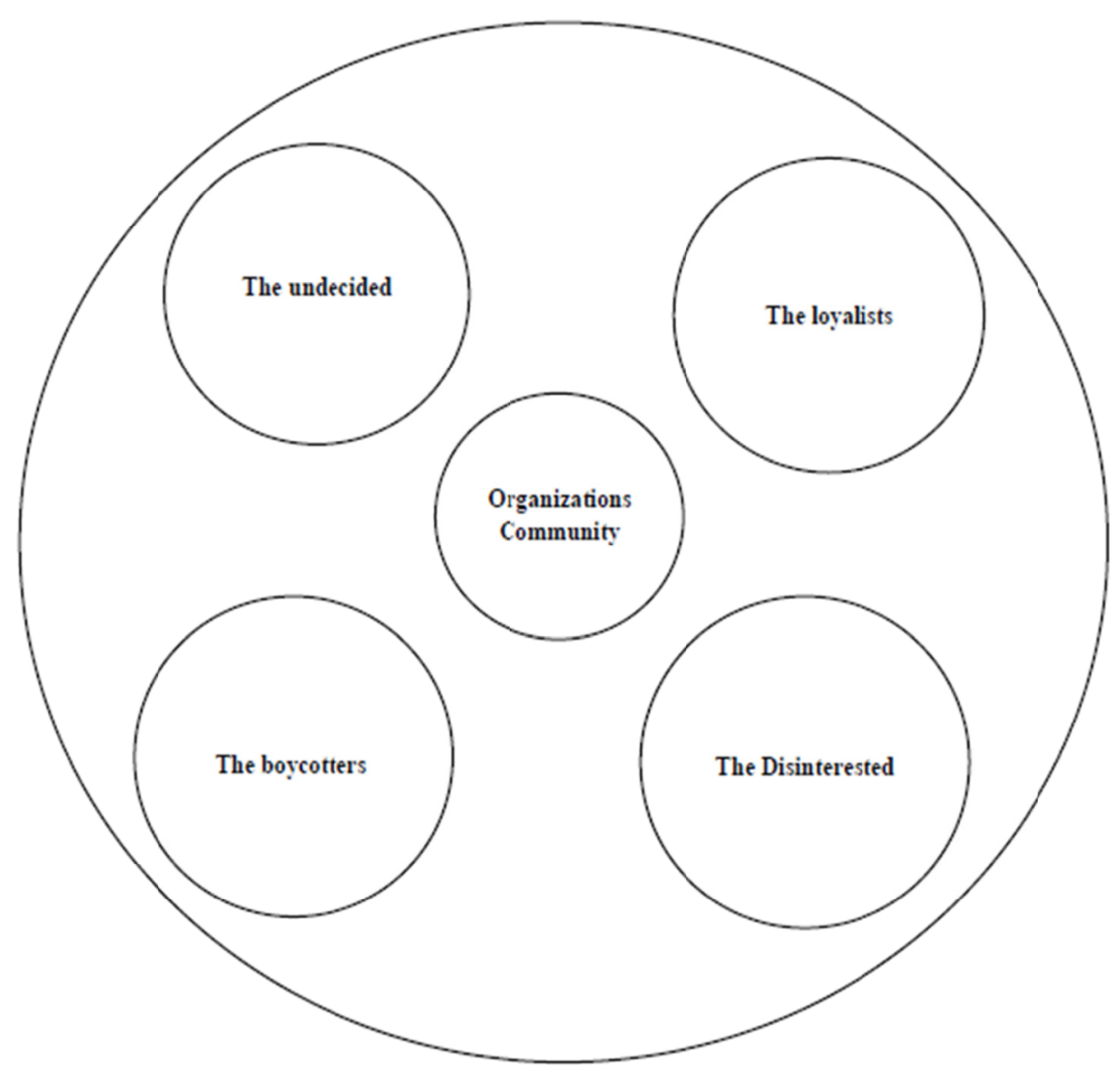

Figure 1. The categories that are targeted by the competitive strategies model suggested

Source: prepared by the researcher.

Based on what been discussed earlier, it is not expected that an organization will follow the same strategies while dealing with these various categories. On the contrary, It should design specific strategies for each category of consumers in order to be able to deal with the different ways of thinking of the individuals of these groups.

Combining and accommodating of the various types of the primary strategic models that the managerial thought presented in one integrated strategic model. This integrated model will be able to differentiate between the various community categories and adopt the appropriate strategy to deal with each one separately at a time. These strategies can be classified as the following:

The competitive strategies for the loyalists category:

a) Customers keeping strategy: a strategy that seeks to protect the organizations loyal customers and maintain high level of satisfaction among them, and focus on the consideration that the customer is a friend who 
deserves positive relation with him in order to guarantee his loyalty to the organization's commodities (Ryall, 2013, pp. 80-83). This strategy includes many programs that are used by the organization to raise the level of satisfaction among the current customers and achieve their permanent loyalty to it, and some these programs as follows:

b) Customers clubs: a strategy based on reinforcing the social relation with the customers. The organization establishes social clubs exclusively for the distinguished customers, and subscriptions determined by and paid to the organizations, such that the customers will be able through it to get priority for commodity buying, receive preferential dealing and service, and the extreme benefit from programs of offers, discounts and general price reductions, etc.

Special rebates programs: it is a program of granting special rebates for the organization customers on the prices of all commodities or some them. The customer gets the rebate once he shows a rebate coupon that he was previously granted from the organization. The coupon can also be used for more privacy and getting more special facilitations.

Purchase repeating rewarding program: a program of granting rewards and gifts to the customers who purchase large and repeated amounts of commodities. The process can also be implemented via smart electronic card or coupons.

Special reductions program: a program of special price reduction for the organization's customers on the commodities in particular days of the year.

Customer relation management strategy: a strategy that aims to build permanent and profitable relations with the customers with aim of keeping them loyal, via providing realized and superior values for them, and achieve the highest fulfilling of their needs, which results in satisfying them continually (Kotler \& Armstrong, 2010).The strategy depends on the principle of continuous interaction and dialogue with the customers, with the purpose of more recognizing and achieving their needs, interests and priorities, and also providing them with all necessary information.

The organization can manage its customer's relations with one of the two following methods:

Human interaction: where the employee becomes an agent between the customer relations management department and the customers themselves. The employee depends on information technology in his interaction with the customer. An example is the call-center service, where customers can call to inquire about the commodity he wants, or to ask some support or to benefit from after sale service, etc. (Azadi \& Rahimzadeh, 2012).

Automated interaction: the customers control the interaction process completely. This requires enabling the customers to use the modern technologies like the Internet or the electronic kiosks in the street (the ATM for example) or the automated systems, to call the organization any time any place and inquire about the commodity that he wants or to advance a support request or make benefit from after-sale service, etc.

Organizations succeed in achieving the desired interaction if the following program were made available:

Granting the customers the full flexibility and freedom in choosing the communication channel he prefers with the organization.

Personal impress dealing: dealing with the customer as a unique person who has his own personality, characteristics, conditions, and personal habits, which should be dealt with interest, respect, and amicability.

Integration of communication means: information integration between all the organization's channels that the customer uses. The customer deals with organization as one unified entity, and that all the organization's members are on a good relation with customer.

Events Marketing: by participating with the customer in his/her occasions of happiness and sorrow, like birthdays, purchasing a new house, return from a voyage, passing of a dear person to him, etc. This requires following the information register of the personal occasions of the customers which continuously occur.

Analysis of customers loss: this can be done via the continuous noticing of the customers who stopped purchasing from the organization or dealing with it, and contacting them to recognize the reasons of that stoppage, and putting the plans and the program that would guarantee their return or control the rate of customers' losing in the future.

Social responsibility strategy: it is a substantial strategy that comes as a resultant of sum of four responsibilities, i.e. the economic responsibility, the legal responsibility, the moral responsibility and the benevolent 
responsibility. These responsibilities work on enhancing the positive mental image of all the community categories about the organization, which will in turn lead to deepening the trust in the organization, and raising the loyalty to it, hence the degree or loyalty to its commodities.Studies and researches showed increasing in the rates of loyalty of the customers of many global organizations which had successfully applied the social responsibility strategies. The studies also showed increases in the rates of old customers keeping, and increases in the rates of the new customers, which finally led to an increase in the market share of those global organizations (Rabeh \& Waheebah, 2012).

Stability strategy: used when the organization's deposit of customers with high loyalty to its commodities stable, and at the same time the organization seeks to keep the competitive position of its commodities, and to enhance the mental image of this category about it. This can be done in two ways:

Stabilizing the price of the commodities that this category maintains buying continuously.

Stabilizing the distribution density of the commodities which this category provide, via maintaining the current distribution network, and working on enhancing and developing its performance in order to insure its impermeability to penetration by the competitors.

Disciplines marketing strategy: used when the organization has a category of customers who not only search for low price, but prefer to refuge to a specialized organization which would relieve them from the responsibilities taking decisions regarding fulfilling their various needs and wants. The core of the strategy lies in that the organization works on providing a group of products with their related services. Consequently, the organization's focus will be on marketing the services that are related with the products that it provides, and these services will be dedicated to ad designed to fulfill the needs and wants of every customer separately, such that the organization will appear to the customer as a devoted consultant who employs all his experiences and programs for solving his various problems. According to this strategy, the organization sells the product to the customer with marketing and selling services like inspection of the appropriateness of his residence for using the product, services of installation and training on using the product, services of maintenance and emergency fault repairs, and it is possible to provide service of buying the used product and resell it a new and enveloped product. As much as the level of these services be persuading to the customers, the ability of this strategy to outperform the competing organizations in the same market will be (Valarie, Zeithaml, \& Leonard, 1985).

Figure 2 shows the sub-strategies that the model direct towards the loyalists' category:

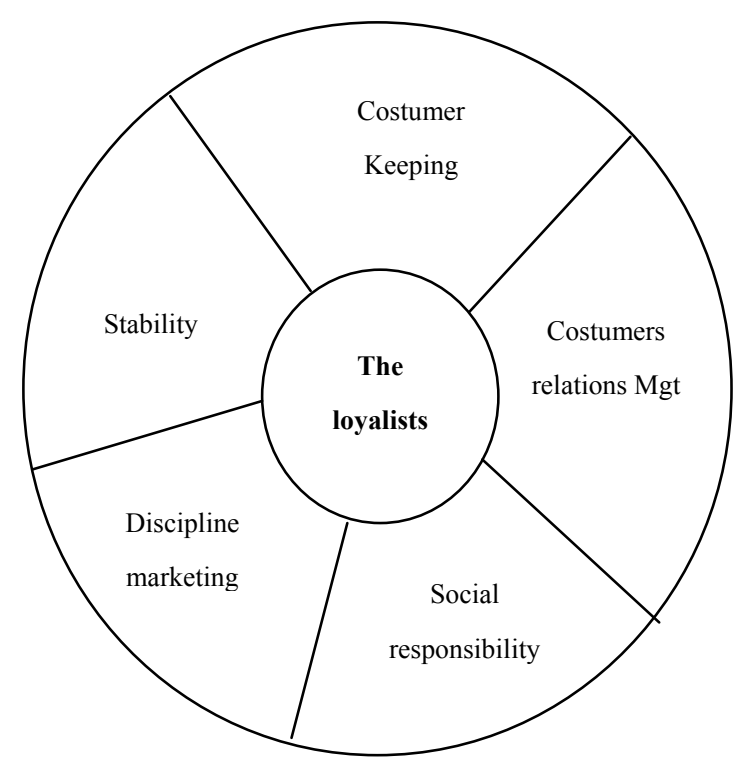

Figure 2. Sub-strategies that the model directs toward the loyalists category

Source: prepared by the researcher.

The competitive Strategies for the undecided category:

a. Variation and pluralism strategy: it focuses on directing the needs and wants of the customers towards 
the organization's commodities, through providing a group of new products with new advantages and additions, to work on fulfilling their changing wants and attracts them toward those products. Based on this strategy, the organization uses two distribution channels or more, such that a complementary channel is dedicated to push out the old products accompanied with a new marketing mix which incorporates providing additional services and lowered prices. The organization also dedicates new distributional channels foe every new product in order to be able to put it in the market extensively and with best image. The application of this strategy helps forming a positive mental image by the irresolute customers who hesitate regarding the organization's ability to provide the old product concurrently with providing new developed products that meet their changing needs and wants (Keskin, 2013).

b. Modification strategy (development): this strategy focuses on making modifications (changes) on a number of commodities that are released to the market with keeping some of them unmodified. The reason that lies behind those modifications could be the emergence of changes in the customers' tastes and needs, or keeping pace with the developments achieved by the competitors. These modifications are accompanied by modifications on the prices and the distributional channels and the promotional mix, therefore the organization works on employing intensive promotional campaigns that shows the new features of its commodities and its superiority over the competitors, and also works on intensifying commodity releasing to the market via employing new agents in its distributional channels, and finally works lowering the prices and gaining low profit margin in favor of market share increasing (Kavoosi et al., 2014).

c. Inspiration strategy: it is a strategy that focuses on adopting the simplified advertising style and the long timed dialogue that are based on facts in persuading people of the commodities that are provided by the organization, introducing them to the benefits and the real advantages of those commodities which differentiate them from the commodities of the other competing organizations, and leading them to fully persuaded real buying (Margherita, 2010).

d. Purchasing simplification strategy: it focuses on reducing search costs that are laid on the buyer, via activating direct delivery of the product at customers' houses usually, and extending before sale and after sale service providing (Guiltnan \& Gordom, 1985).

e. Direct targeting strategy: it is a strategy that determine particular categories of people and study their real needs and directly target them with definite types of commodities and with fixed prices too, provided that these products be in agreement with those needs in terms of their characteristics, specifications and prices (Azadi \& Rahimzadeh, 2012).

Figure 3 shows the sub-strategies that the model directs towards the undecided people category.

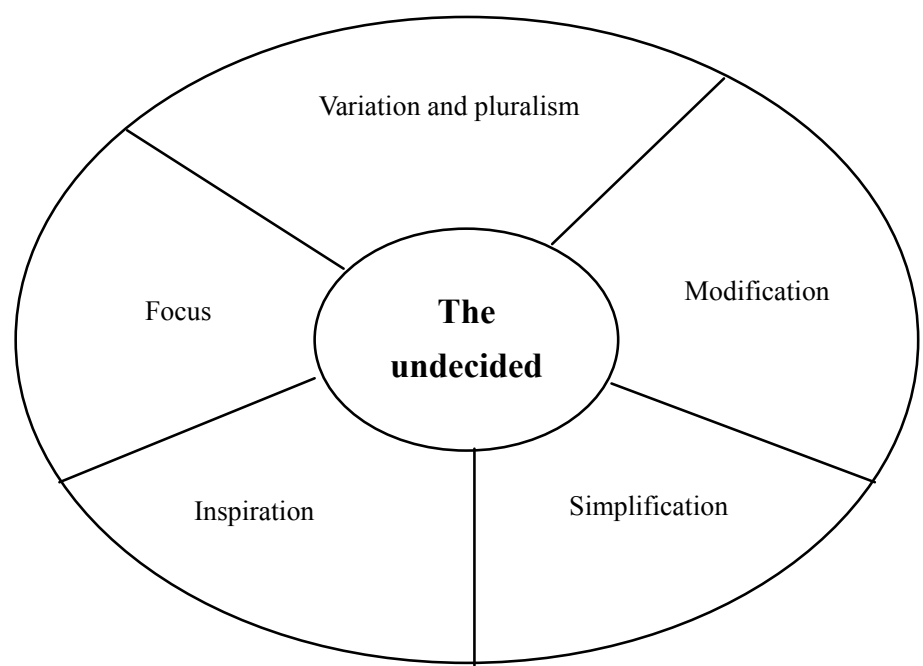

Figure 3. Sub-strategies that the model directs towards the undecided people

Source: prepared by the researcher. 
The competitive strategy for the disinterested people category:

It includes the following strategies:

a. Increasing the number of the consumers: it is a strategy that focuses on increasing the consumers wants to buy via illustrating and highlighting the various benefits that the product provides, as well as focus on enabling the consumers to buy the organization's commodities through presenting price offers that suit their purchasing abilities, accompanied with intensive distribution and rebated delivery operations, or through comfortable installment (Baroto et al., 2012).

b. Attraction strategy: it is a strategy that focuses on enabling the organizations to create direct demand from the consumer via intensive promotional activities and with aid of the retailers, thereby attracting consumers and push them to demand commodities under the enthrallment effect (Keskin, 2013).

c. Distribution and the intensified push (substantial) strategy: it focuses on substantial coverage of the market, and usually used on the competition on the simplified products market, such that the organization's products are showed intensively through the largest number of distribution channels and distributes, in order to push the customers towards buying them at any time and any place in the market, along with employing promotional campaign (personal selling, advertisement, etc.). The competitive advantage is achieved as a result of the fact that they do not require specialized knowledge to sell them, as well as do not require after sale services (Margherita, 2010)

d. Social responsibility strategy: it is an utter strategy which is the resultant of the sum of four responsibilities, i.e. the economic responsibility, the legal responsibility, the moral responsibility and the benevolent responsibility. This responsibility works on enhancing the positive mental image of all the community categories about the organization, which results in deepening trust sin the organization, increasing loyalty to it, thereby increasing loyalty towards its commodities (Sulistyowati et al, 2013).

e. Simplification strategy: it focuses on reducing search costs that are laid on the buyer, via activating direct delivery of the product at customers' houses usually, and extending before sale and after sale service providing (Guiltnan \& Gordom, 1985).

f. Market leadership via overall cost strategy: it is the strategy presented by Porter (1980) within his model. It focuses on organization's supremacy and increasing its market share based on increasing the number of customers, through providing commodities with lowered prices which is achieved as a result of reducing the overall cost.

Figure 4 shows the sub-strategies that the model direct towards the disinterested people category. 


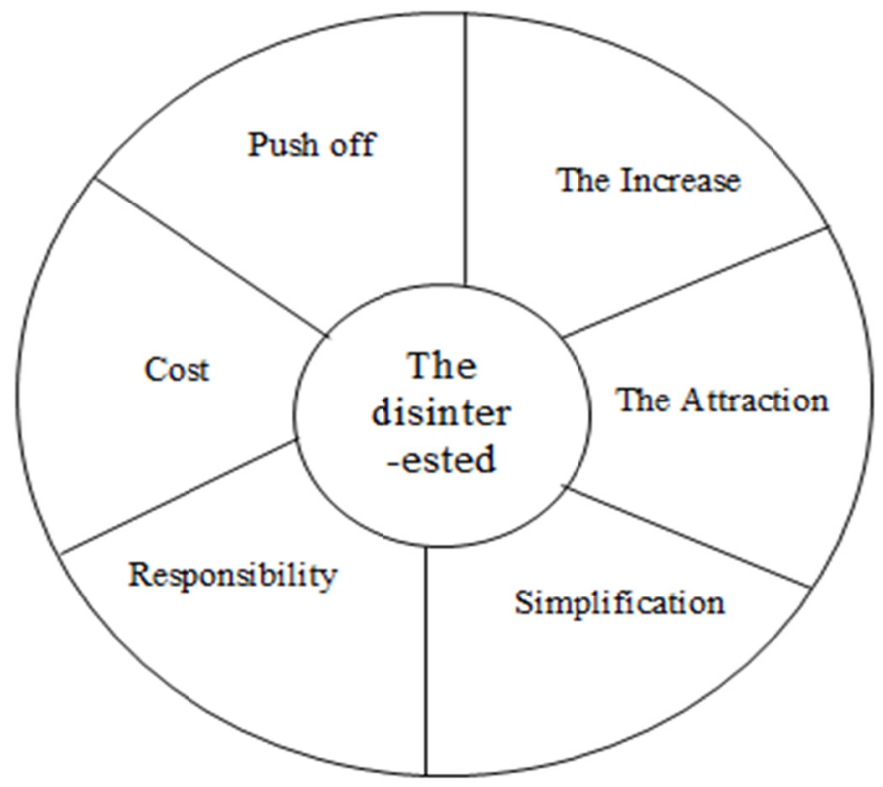

Figure 4. Sub-strategies that the model direct to disinterested people category

Source: prepared by the researcher.

The Competitive strategy for the boycotting category

a. Goals unification strategy: focuses on linking the organization's goals with the workers' goals and the community's goals, therefore inducing workers' assiduity in marketing the organization's commodities and working on persuading the boycotting individuals of the community to buy the organization's products or services, from a viewpoint that the organization's goal is develop the community with all its elements and classes (Sulistyowati et al, 2013).

b. The flowing commodities strategy: focuses on releasing a flood of new product or services, which results in the swift obsolescence of those products as well as the obsolescence of the competitors' products. The organization also employs continuing $R \& D$ processes to derive creative ideas and effective innovations that would reduce the times needed for product design and production processes and decrease their costs (Treacy \& Weisermay, 1995)

c. Product position conquer strategy: focuses on providing commodities with the same quality and price of the competitors' prices, along with one or more features, or excellence in the marketing program (Guiltnan \& Gordom, 1985).

d. Pressure Strategy: focuses on organizational adopting of the strong persuasion of people by provided commodities of the organization and introducing them to the real benefits of those commodities and their distinguished features (Keskin, 2013)

e. Personal selling strategy: focuses on the necessity of using the direct influencing on the buyers, such that to directly face them, open dialogue channels with them, then trying to persuade them to buy the product through effective demonstration and negotiation. From here, the personal selling strategy represents a more effective promotional tool, because it enables the organization to direct connection with the buyers without the need to refuge to the distributional channels which does not give the organization's products their adequate share of marketing and customer persuasion (Ferrell, 1993).

f. Market leadership by low cost strategy: it is one of the strategies that Porter presented. It focuses on the organization's superiority and its increasing market share that is based on increasing the number of customers through providing commodities with lowered prices, which could be achieved as a result of achieved reductions in the overall cost (Kavoosi et al., 2014).

g. Market leadership by differentiation strategy: it is one of the strategies that Porter (1980) presented. It focuses on the organization's differentiation and uniqueness among the competitors, such that it will enable the organization to increase the customers who have willingness to buy and possess the 
differentiated commodities regardless of the prices. It relies in building its competitive advantage on making the customers more loyal to its commodities and also less sensitive to their prices.

Figure 5 shows the sub-strategies that the model direct towards the boycotters' category.

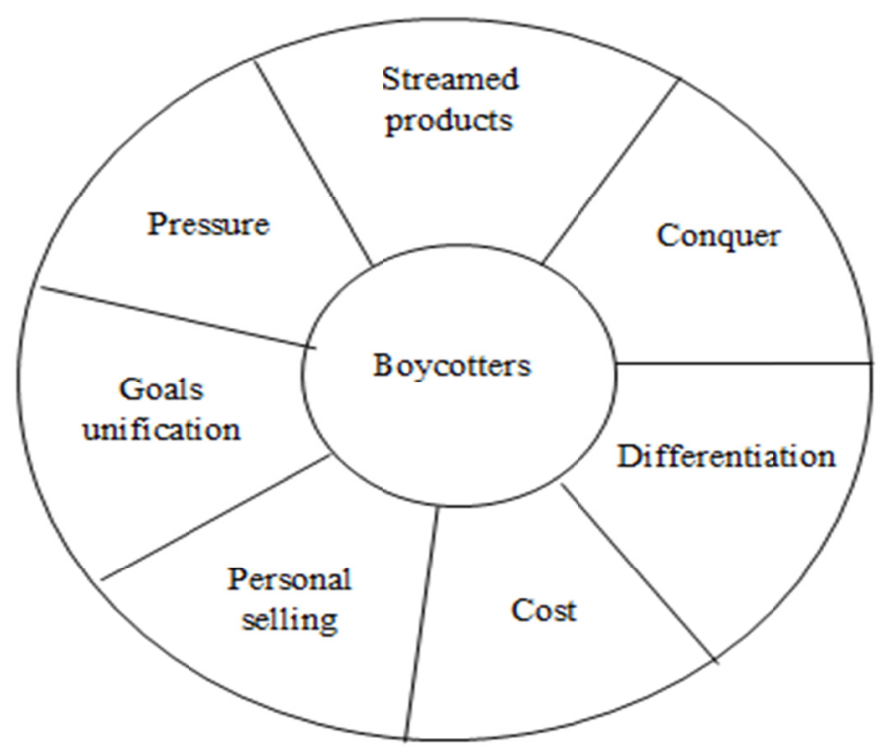

Figure 5. Sub-strategies that the model directs toward the boycotters category

\subsection{The Integrated Model for the Competitive Strategies}

With the completion of the construction of this model, its comprehensiveness reveals because it targets all the organization community categories, not just customer category. Its integration also reveals through its ability to distinguish between different categories of society and to adopt the appropriate strategy to deal with each category separately. 


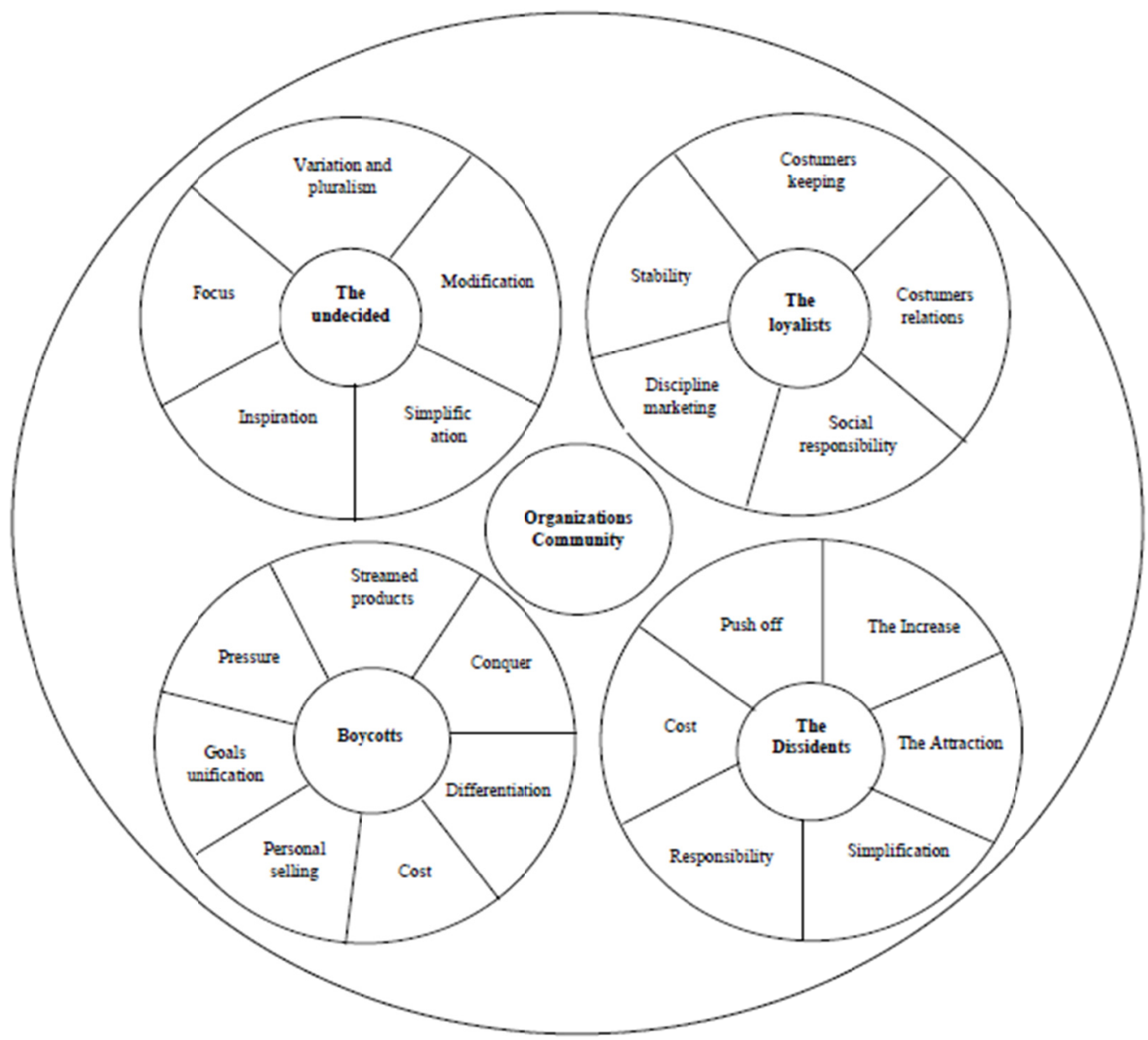

Figure 6. The integrated model for the competitive strategies

Source: prepared by the researcher.

\section{Conclusions}

The study suggests a new model of "Competitive Strategies" that didn't exist before. This model will help interested organizations in building a competitive strategies for comprehensiveness and substantiality.

\section{Recommendations}

i. Work on the practical test of the proposed of competitive strategies in this study.

ii. Continue operation in scientific research in order to link to several innovation models contribute in the providing innovation competitive strategies that help modern companies in enhancing their competitive models.

\section{References}

Assaf, A. M. (2013). TQM Philosophy As the Islamic Management Model. Excellence and entrepreneurship in business o organizations supremacy workshop conference. The World Islamic Sciences \& Education University, Jordan.

Azadi, S., \& Rahimzadeh, E. (2012). Developing Marketing Strategy For Electronic Business By Using McCarthy's Four Marketing Mix Model And Porter's Five Competitive Forces. Emerging Markets Journal, 2, 47-58.

Baroto, M. B., Abdullah, M. M., \& Wan, H. L. (2012). Hybrid Strategy: A new Strategy for Competitive Advantage. International Journal of Business and Management, 7(20), 120-133. http://dx.doi.org/10.5539/ijbm.v7n20p120

Duncan, W. J. (1989). Great ideas in management: Lessons from the founders and foundations of managerial 
practice. San Francisco: Jossey-Bass.

Ferrell, O. P. (1993). Marketing: Concepts and Strategies (8th ed.). U. S: Houghton Mifflin Company.

Guiltnan, J. P., \& Gordom, W. P. (1985). Marketing Management: strategies and programs (2nd ed). USA: McGraw-Hill.

Kanter, R. M. (1987). The Case Against Cowboy Management. Management Review, 76(6), 21-23.

Kavoosi, S., Sadeghian, S., \& Mahmudi, K. (2014). An Empirical Investigation of the Impact of Customer Orientation, adaptive selling behaviors, and job satisfaction on salespeople's performance: The Moderating Role of Selling Experience. International Journal of Research in Management, 4(3), 74-88.

Keskin, H. (2013). Examination of Competitive Advantage of the Forest Products Industry in Western Mediterranean Region in the Framework of Porter's Diamond Mod. International Journal of Alanya Faculty of Business, 5(2), 51-66.

Kotler, P., \& Armstrong, G. (2010). The Principles of Marketing (13th ed). Upper Saddle River/NJ: Prentice Hall.

Margherita, S. (2010). The Liberalization of Tariff Rate Quotas Under Oligopolistic Competition. Journal Article in Journal of Agricultural Economics, 61(3), 584-604.

Miles, R. E., \& Snow, C. C. (1978). Organizational Strategy, Structure, and Process. New York: McGraw-Hill.

Najem, N. (2006). Ethics of Management and Business Responsibility in Business Organizations. Amman, Jordan, Al-warraaq publishing Co., Arabic Encyclopedia.

Porter, E. M. (1980). Competitive Strategy: Techniques for Analyzing Industries and Competitors. New York: Free Press.

Porter, E. M., \& Heppelmann, E. J. (2014). How Smart, Connected Products Are Transforming Competition. $H B R, 66-88$.

Rabeh, A., Ben, D., \& Haybah, A. (2012). The Social Responsibility of the Organizations and Its Role in in Development: A Demonstration of the Experience of some Global Companies. The Third International Forum for the faculty of Economic, commercial and Leadership Sciences, University of Bashshaar, Algiers, Algeria.

Ryall, M. D. (2013). The New Dynamics of Competition An emerging science for modeling strategic moves. $H B R, 80-87$.

Singer, A. E. (2013). Corporate political activity, social responsibility, and competitive strategy: an integrative model. Business Ethics: A European Review, 22(3), 308-322.

Sulistyowati, K., Salim, U., Surachman, A., \& Solimun, A. (2013). Competitive Strategy: As Mediation the Effect of External Business Environment and Total Quality Management Implementation Toward Company Performance (Study at ISO 9000 certified manufacture companies in East Java). IOSR Journal of Business and Management (IOSR-JBM), 8(2), 7-20. Retrieved from http://www.iosrjournals.org/iosr-jbm/papers/Vol8-issue2/B0820720.pdf

Thurow, L. (1992). Head to Head: the coming economic battle among Japan, Europe, and America (pp. 270-279). New York, William Morrow.

Treacy, M., \& Wiersema, F. (1995). The Discipline of Market Leaders. New York: Addison Wesley Company, Inc.

Valarie, A., Zeithaml, A., \& Leonard, L. (1985). Problems and Strategies in Services Marketing. Journal of Marketing, 49(22), 33-46.

\section{Copyrights}

Copyright for this article is retained by the author(s), with first publication rights granted to the journal.

This is an open-access article distributed under the terms and conditions of the Creative Commons Attribution license (http://creativecommons.org/licenses/by/3.0/). 